\title{
Excessive accelerations in bridges for Korea high-speed railway
}

\author{
J. W. Kwark ${ }^{1}$, J. R. Cho ${ }^{1}$, W. J. Chin ${ }^{1}$, B. S. Kim ${ }^{1}$ \& E. K. Cho ${ }^{2}$ \\ ${ }^{1}$ Korea Institute of Construction Technology, Republic of Korea \\ ${ }^{2}$ Hyundai Engineering \& Construction Co. LTD., Republic of Korea
}

\begin{abstract}
When the Korean high-speed train (KTX) runs over a high-speed railway bridge, the high-speed railway bridge gives quite a large acceleration response. Local vibration at the large cross section, the impact from equally spaced sleepers, the vibration due to elastomeric bearings, and the vibration from the train itself are the causes of this acceleration response. Maximum peaks of the accelerations measured at the bridges are sometimes going over the limit value. Although it is smaller than 0.35G, the limit from the Korean Bridge Design Manual (BRDM), this acceleration response should be reduced for the safety of running trains with high-speed. In this paper, to reduce the acceleration response by controlling excessive local vibration at the large cross section, the vibration reduction method is studied. The result shows that the effect of elastomeric bearings on the vibration of the bridge is very large and that the vibration reduction device is effective against a wing mode local vibration PSC box girder bridge for the high-speed railway, which usually has a very large cross section, although it has little effect on global vibration modes such as flexural and twisting modes. The test of the vibration reduction device on the bridge in service has been performed in this study.
\end{abstract}

Keywords: high-speed train, dynamic behaviour of bridge, reduction of vibration, damper, box-girder bridge, excessive acceleration.

\section{Introduction}

Approximately one-third of the whole length of the Gyeongbu high-speed railway line, which opened to traffic on April 1, 2004 in Korea, is constituted by 
bridge structures. Except for particular sections like stations, crossings of highways and expressways, the elevated bridge structures have been typically built as PSC box girder bridges with span compositions of 2@40 m or 3@25 m. Especially, PSC box girder bridges with span composition of 2@40 m can be considered as the most representative bridge type among the bridges that have been designed and built on the Gyeongbu high-speed railway line. This selection has been decided since the design stage after comparative survey of various bridge types presenting reduced construction costs like PSC beam, preflex, T-shape girder, rahmen and PSC box girder bridges. Comparison finally resulted in the choice of PSC bridges due to the remarkable stability of their dynamic responses. Although diversified construction methods have been implemented according to the builders and site conditions, identical features and characteristics, that are single box with girder height of $3.5 \mathrm{~m}$ and width of $14 \mathrm{~m}$, have been applied for the bridges. Such large sectional shape led to long span of about $7 \mathrm{~m}$ for the floor slab between the webs of the box girder and overhanging beams exceeding a length of $3 \mathrm{~m}$ in both sides.

Differently from ordinary highway bridges crossed by indeterminate wheels on variable lanes, railway bridges present determinate loading conditions since trains are running on assigned tracks. In addition, at an arbitrary point of the bridge, vehicles running on a highway bridge act irregularly as punctual dynamic loads while trains are producing repeated dynamic loads through their regularly spaced wheels moving on a determinate track. Trains are thus acting as loading with definite frequency. However, if this frequency coincides with the natural frequency of the bridge, resonance will occur, producing excessive responses of the bridge and causing disastrous effects on the safety of the train crossing the bridge. As the dynamic response characteristics of the bridge depend on the relationship between its natural vibration modes (especially flexural modes) and the frequency of the applied load, it is necessary to perform investigations on the dynamic behavior of the bridge in order to secure running safety of the trains when deciding the type of high-speed railway bridge. To that goal, selected criteria have been set up in BRDM based on the European UIC. The major specifications related to the safety of the track are the acceleration of deck $(0.35 \mathrm{~g})$, the deflection $(\mathrm{L} / 1700)$ and the end rotation $\left(5 \times 10^{-4}\right.$ radian $)$.

In spite of the importance of safety for high-speed railway bridges, studies on the dynamic behavior of high-speed railway bridges were practically neglected until the early 1990s. Recently, Chang et al. [1] proposed a two-dimensional train model considering bouncing and pitching motions to perform vibration analyses of bridges subject to moving articulated bogies train. In this study, the ballast covering the bridge was idealized by means of the classical theory of beam on elastic foundation. Thereafter, Ahn et al. [2] and Kim [3] attempted to suppress resonance by relating the span length of the bridge and the arrangement of the train. However, most of these studies remain theoretical and the absence of experimental studies is particularly overwhelming. Kwark et al. [4] proposed a first attempt to fill this void through experimental researches performed to investigate the dynamic responses of concrete box-girder bridges in 2003. 


\section{Field measurement on the dynamic responses}

Running tests were performed in the test lane of the Gyeonbu high-speed railway line in order to check and inspect the trains, structures and facilities before the opening to traffic in 2004. Measurements of the dynamic responses of Yeon-Jae Bridge as shown in Fig. 1 crossed by the KTX, the Korean version of the French TGV, were carried out since 2002. Yeon-Jae Bridge is a PSC box girder bridge with span length of 2@40 m located in the experimental section of the Gyeonbu high-speed railway line.
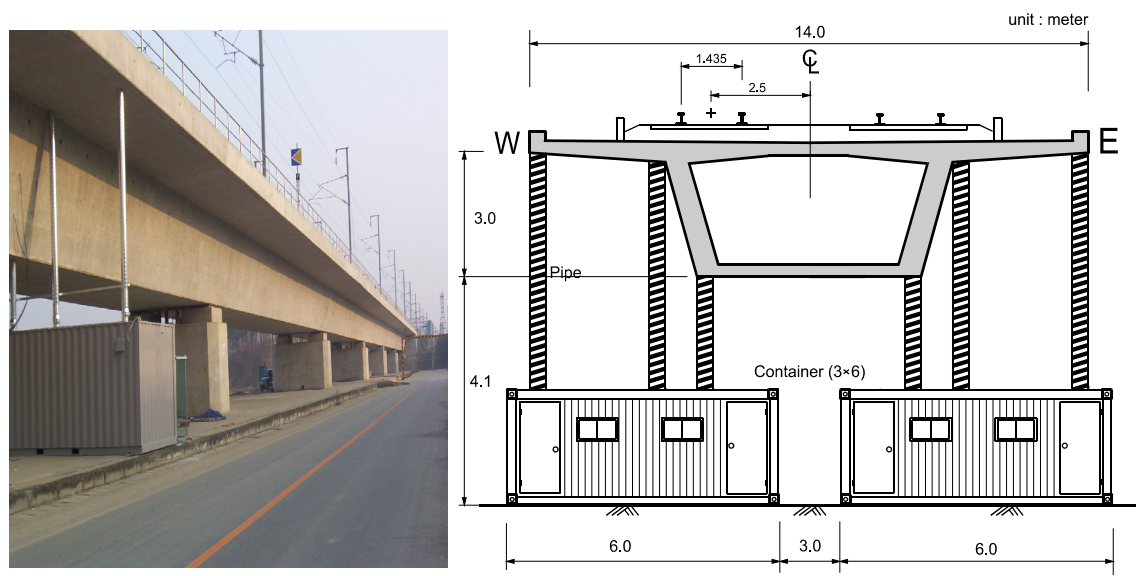

Figure 1: General view and measurement system of Yeon-Jae Bridge.

Diversified types of sensors like displacement transducers, accelerometers and end rotation measuring devices were installed in Yeon-Jae Bridge for site measurement. Measurements were performed irregularly during the running tests and at fixed intervals after the beginning of operational service.

Measurement results of the bridge responses obtained through the sensing devices during the crossing of the KTX revealed that, except for the acceleration, all the responses exhibited sufficient level to secure running safety. Measured deflections and end rotation were seen to be largely below L/1700 and $5 \times 10^{-4}$ $\mathrm{rad}$, respectively. However, excessive acceleration responses were measured, which in extreme cases exceeded the limit specified by BRDM.

\section{Excessive acceleration of the bridge due to running KTX}

Excessive acceleration responses in PSC single box girder bridges were observed through site measurements during the preliminary tests performed in 2002 to examine the dynamic responses of high-speed railway bridges due to the crossing of the KTX. The occurrence of such phenomenon could be explained by the fact that measurements were carried out before operational service for trains without variation of their loads, and decision was taken to pursue long-term 
measurement. As a result, excessive accelerations were measured in winter as temperature decreased. Fig. 2 plots the maximum acceleration responses measured in Yeon-Jae Bridge according to time.

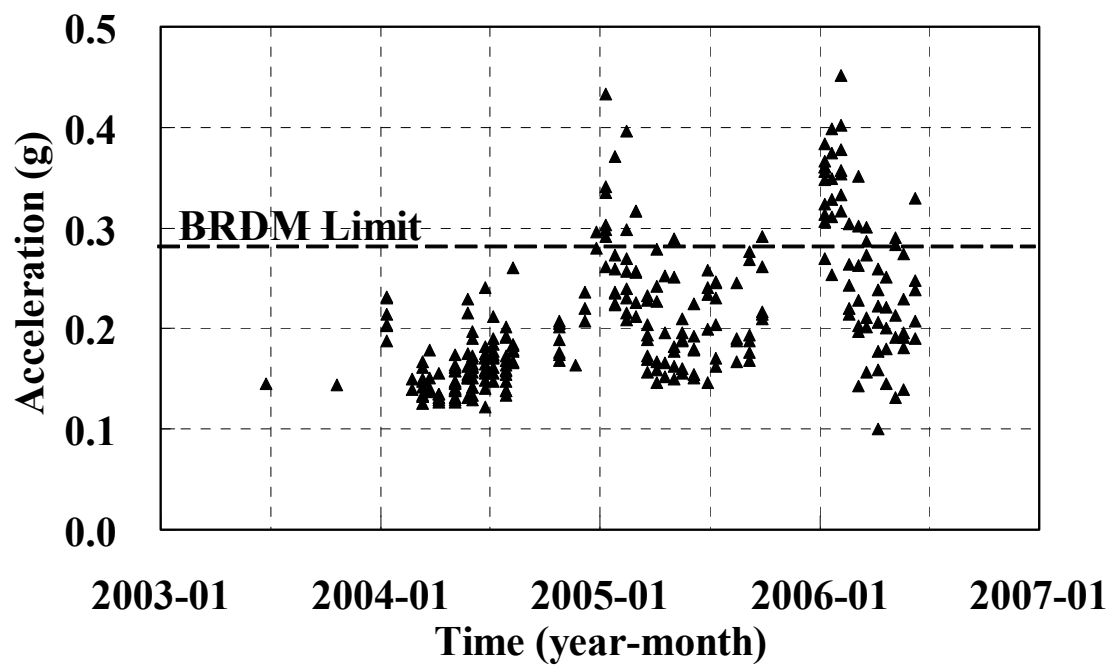

Figure 2: $\quad$ Variation of maximum acceleration responses with time.
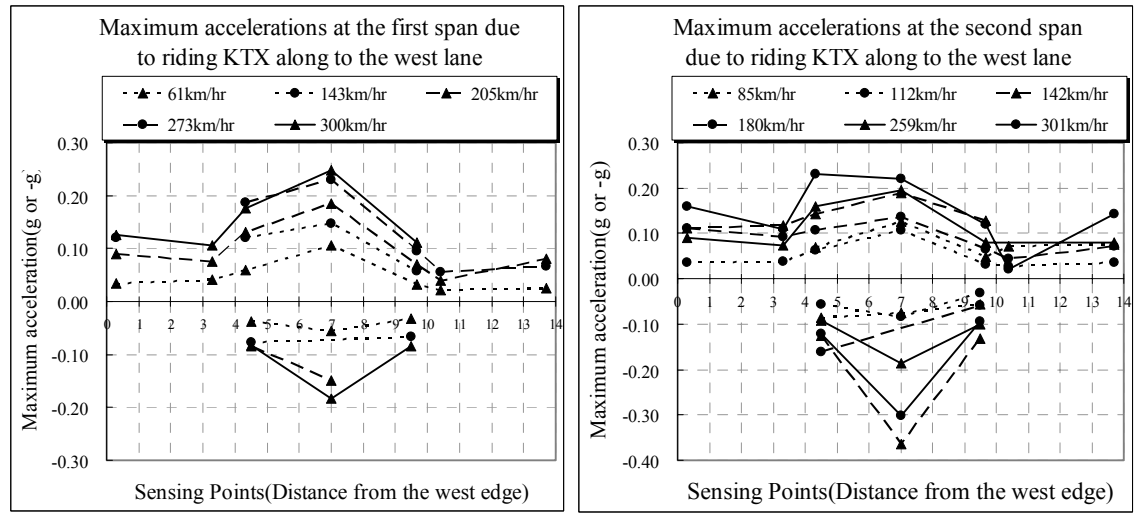

Figure 3: Distribution of the maximum acceleration in the section of YeonJae Bridge according to the crossing of KTX.

On the other hand, even if accelerations were seen to surpass the limit value under very low temperatures, acceleration responses were also observed to be very large and approach the limit of $0.35 \mathrm{~g}$ under normal temperatures. The reasons can be found in the conditions of the wheels and rails like side wear, the interface conditions between the ballast and the sleepers, the maintenance conditions of the ballast and the type of bridge. Most of these reasons depend on the state of the ballast and train rather than on the type of bridge. Measurements 
revealed that perfect adhesion of the sleepers with the ballast could not be obtained, which led to impacts on the bridge each time wheels ran over the sleepers. Following, the regularly and continuously spaced sleepers together with the speed of the moving wheels were seen to affect the acceleration responses of the bridge. Moreover, local vibrations were predicted in Yeon-Jae Bridge since its section corresponds to a very large single box girder bridge. This prediction and the influence of the sleepers disposed at regular intervals were verified in view of the measurements plotted in Fig. 3.

\section{Reduction of acceleration using damping devices}

The acceleration responses occurring in Yeon-Jae Bridge under resonance appeared to be extremely large. Such resonance frequency corresponds to the first mode of the bridge under resonance speed. Three alternatives may offer solutions in order to prevent or reduce these excessive accelerations, which are preventing resonance, installing vibration-reducing devices, or adding masses in the inner sections of box-girder. Even if adjusting the stiffness of the bridge or adopting the recently reported resonance cancellation span length may prevent resonance, the former is economically inefficient and the latter cannot be applied on completed bridges. On the other hand, the methods which proceed by introducing isolating device, or added masses in the whole system of previously built bridges develop their performances only when the defection exceeds a definite level. However, in the bridge of interest, the stiffness being extremely large, deflection reaches barely several millimeters, which renders such method unpractical. Recalling that local vibrations and large accelerations occur in the bridge, a solution can thus be provided by reducing such local vibrations which will in turn reduce these excessive acceleration responses.

The reducing effects on the local vibrations have been examined by applying external forces with frequencies corresponding to bending, torsion and flap modes at locations occupied by the moving train. The adopted isolating device is a viscous damper sustained between the top and bottom flanges at the center of the section of the bridge. A damping value of $5 \times 10^{8} \mathrm{~N} \cdot \mathrm{sec} / \mathrm{m}$ has been considered regard to the specs provided for actually commercial viscous dampers.

For a study on the method of vibration reduction of the bridge, a computer program for dynamic analysis of the bridge due to moving loads of high-speed trains was developed considering local vibration of box-girder and simulating damper device. Applicability of damper device to vibration diminution was evaluated numerically using the developed program. Dynamic responses according to trains running at various speeds from $150 \mathrm{~km} / \mathrm{hr}$ to $400 \mathrm{~km} / \mathrm{hr}$ were analyzed for the bridge installed with one and three dampers (case1 and case 3, respectively) or without damper (case 0). Fig. 4 plots the time histories of bridge accelerations due to high-speed train crossing with speed of $275 \mathrm{~km} / \mathrm{hr}$ according to the eventual presence of damper device. Fig. 5 shows the reduction ratio of bridge accelerations brought by the set of dampers according to the speed of the train. 


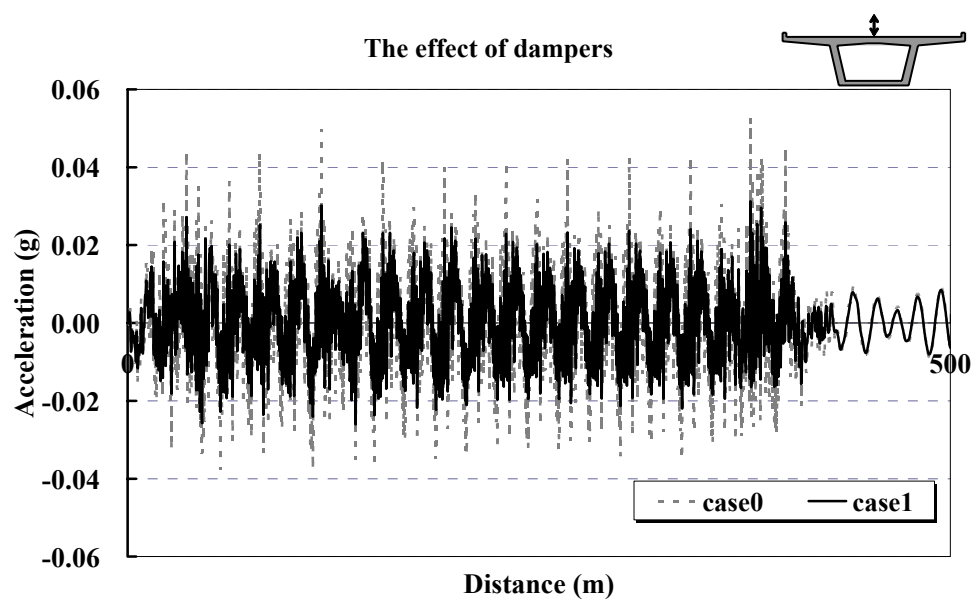

Figure 4: Comparison of accelerations of case 0 (without damper) with case 1 (with one damper).

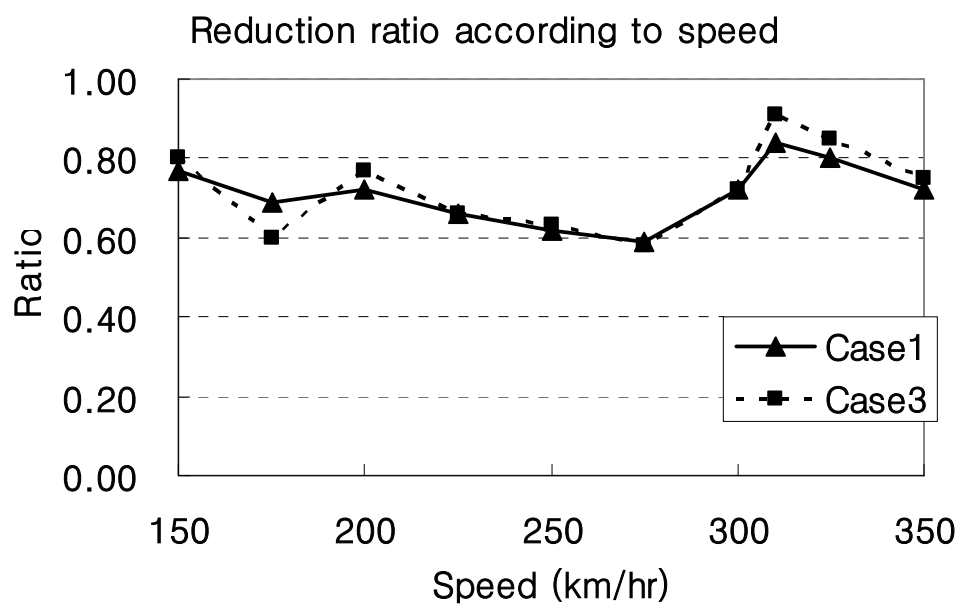

Figure 5: Reduction of accelerations provided by the set of dampers.

In order to examine the performances of the damping devices in reducing the local vibrations, various dampers were installed in the $2 @ 40 \mathrm{~m}$ PSC box girder bridge and running tests were conducted. Fig. 6 illustrates schematically the installation of the dampers. One damper was disposed in each span.

A total of 8 load cases were considered. Table 1 arranges the reduction ratios of the vibrations caused by actually running high-speed trains obtained through the application of the dampers. Regard to the field tests, results verified that the vibration reduction effect reached a maximum of $26 \%$ owing to the use of the local vibration-reducing devices. 


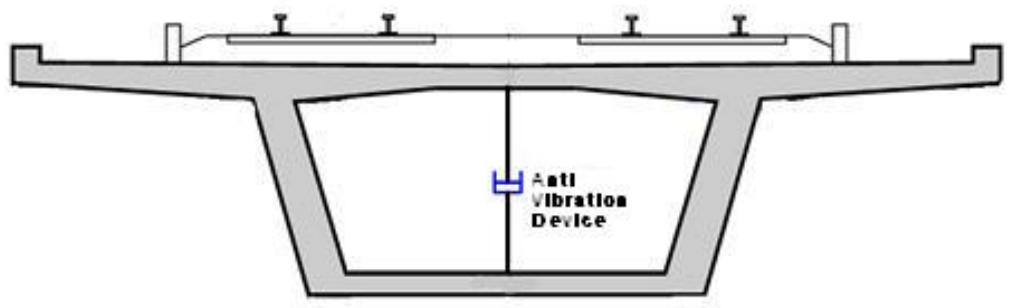

Figure 6: Installation setup of the dampers for the reduction of local vibrations.

Table 1: Vibration reduction ratio according to the damping devices.

\begin{tabular}{|c|r|c|}
\hline Case & $2^{\text {nd }}$ span & $1^{\text {st }}$ span \\
\hline Orifice damper $\Phi 0.5$ & $4.17 \%$ & $7.32 \%$ \\
\hline Orifice damper $\Phi 1.0$ & $25.85 \%$ & $11.12 \%$ \\
\hline Orifice damper $\Phi 1.5$ & $6.88 \%$ & $2.72 \%$ \\
\hline Orifice damper $\Phi 2.0$ & $13.65 \%$ & $10.68 \%$ \\
\hline Turnbuckle & $-0.12 \%$ & $11.16 \%$ \\
\hline Rigid linkage & $5.39 \%$ & $15.43 \%$ \\
\hline Urethane & $8.91 \%$ & $10.15 \%$ \\
\hline Rubber & $8.81 \%$ & $23.53 \%$ \\
\hline
\end{tabular}

\section{Reduction of acceleration by installing added masses}

The damping devices proposed to reduce the local vibrations were seen to produce effects to a certain extent regard to the field test results. However, these vibration reduction effects are lacking consistency, which makes such solution of poor efficiency in long-term, especially in view of the difficulties that are likely to occur in the maintenance. Since the vibration accelerations observed in the actual bridges of the Gyeongbu high-speed railway line are approaching or exceeding slightly the design values, necessity is to provide economically efficient as well as effective solution for maintenance while obtaining only vibration reduction effect. A solution can be supplied by increasing the mass of the bridge without changing its stiffness so as to realize reduction of the acceleration responses. Most of the bridges of the Gyeongbu high-speed railway line being box girder bridges, sufficient space can be secured inside the boxes to implement works. Accordingly, this space has been exploited to increase the mass of the bridges. A trial construction is planned on an actual bridge in the mid of 2007, and the expected effects of this solution have been verified theoretically through analytic study to date. 
Fig. 7 illustrates schematically the laying of the additional masses. The added masses are laid inside the box girders above the bottom flange at 2 spans. The masses with length of $10 \mathrm{~m}$, thicknesses of $25 \mathrm{~cm}$ (T25) and $50 \mathrm{~cm}$ (T50) are made of ordinary concrete so as to prevent change of the stiffness.

Table 2 summarizes the values used to model analytically the bridges for the verification of the vibration-reducing effects of the bridges using the additional masses. The ratio of the additional masses to the whole self-weight reaches approximately $1.3 \%$ for the case with thickness of $25 \mathrm{~cm}$, which corresponds to a very slight augmentation of the dead load while the first flexural frequency increases by about $14 \%$.

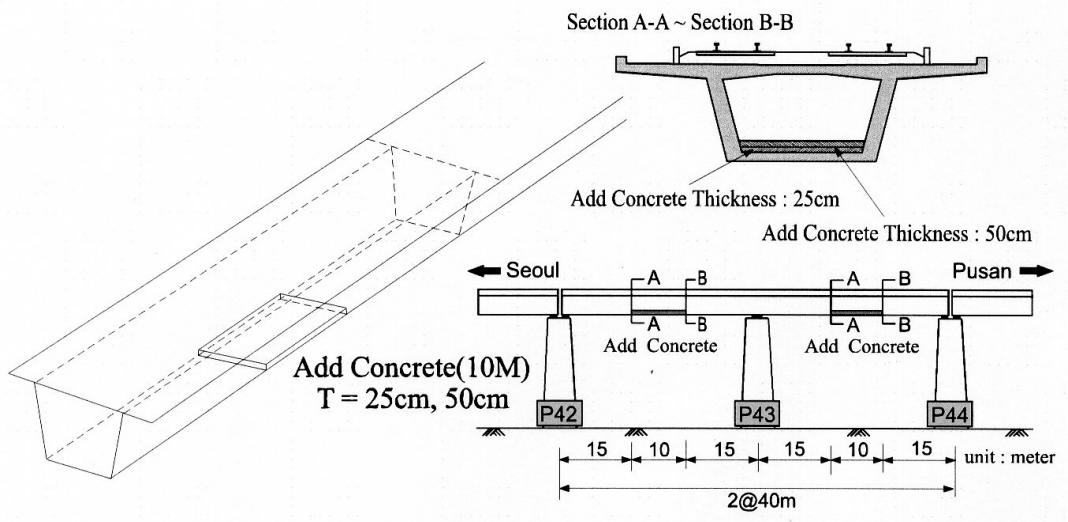

Figure 7: Schematic drawing of the performance improvement of existing bridges using additional masses.

Table 2: Analytic model applying the additional masses.

\begin{tabular}{|c|c|c|c|c|c|c|c|}
\hline $\begin{array}{l}\text { Mo } \\
\text { del }\end{array}$ & $\begin{array}{l}\text { Nat. } \\
\text { Freq. } \\
(\mathrm{Hz})\end{array}$ & $\begin{array}{c}\text { Added } \\
\text { Mass } \\
(\%)\end{array}$ & \multicolumn{5}{|c|}{ Remarks } \\
\hline T0 & 4.49 & 0.0 & $\xi$ & & $\xi$ & & $\xi$ \\
\hline \multirow[b]{2}{*}{ T25 } & \multirow[b]{2}{*}{3.87} & \multirow[b]{2}{*}{1.3} & \multirow{2}{*}{$=3$} & & \multicolumn{3}{|c|}{$10 \mathrm{~m}$} \\
\hline & & & & $0.25 \mathrm{~m}$ & $\xi$ & $0.25 \mathrm{~m}$ & $\xi$ \\
\hline \multirow[b]{2}{*}{ T50 } & \multirow[b]{2}{*}{3.81} & \multirow[b]{2}{*}{2.6} & \multirow{2}{*}{$\xi$} & & \multicolumn{3}{|c|}{$\stackrel{10 \mathrm{~m}}{\longleftrightarrow}$} \\
\hline & & & & $0.5 \mathrm{~m}$ & $\xi$ & $75 m$ & $\sigma^{2}$ \\
\hline
\end{tabular}

Fig. 8 plots the acceleration response ratio according to the additional masses in the top flange at mid-section of the span under high-speed train running at 300 $\mathrm{km} / \mathrm{hr}$. It can be seen that the maximum response ratio of the models T25 and T50 are reducing respectively by $37 \%$ and $43 \%$. Table 3 arranges the maximum reduction ratio for each model. 
Table 3: Maximum reduction ratio of the acceleration according to the added masses.

\begin{tabular}{|c|c|c|c|c|c|}
\hline \multirow{2}{*}{ Model } & \multirow{2}{*}{$\begin{array}{c}\text { Speed } \\
(\mathrm{km} / \mathrm{hr})\end{array}$} & \multicolumn{4}{|c|}{ Reduction ratio (\%) } \\
\cline { 3 - 6 } & & \multicolumn{2}{|c|}{ Cantilever } & \multicolumn{2}{c|}{ Center of upper flange } \\
\cline { 3 - 6 } & $1^{\text {st }}$ span & $2^{\text {nd }}$ span & $1^{\text {st }}$ span & $2^{\text {nd }}$ span \\
\hline \multirow{2}{*}{ T25 } & 300 & -20.8 & -28.8 & -36.6 & -20.3 \\
\cline { 2 - 6 } & Resonance & -9.8 & -14.9 & -7.6 & -5.8 \\
\hline \multirow{2}{*}{ T50 } & 300 & -42.9 & -45.6 & -38.2 & -24.0 \\
\cline { 2 - 6 } & Resonance & -11.5 & -32.5 & -9.4 & -7.4 \\
\hline
\end{tabular}
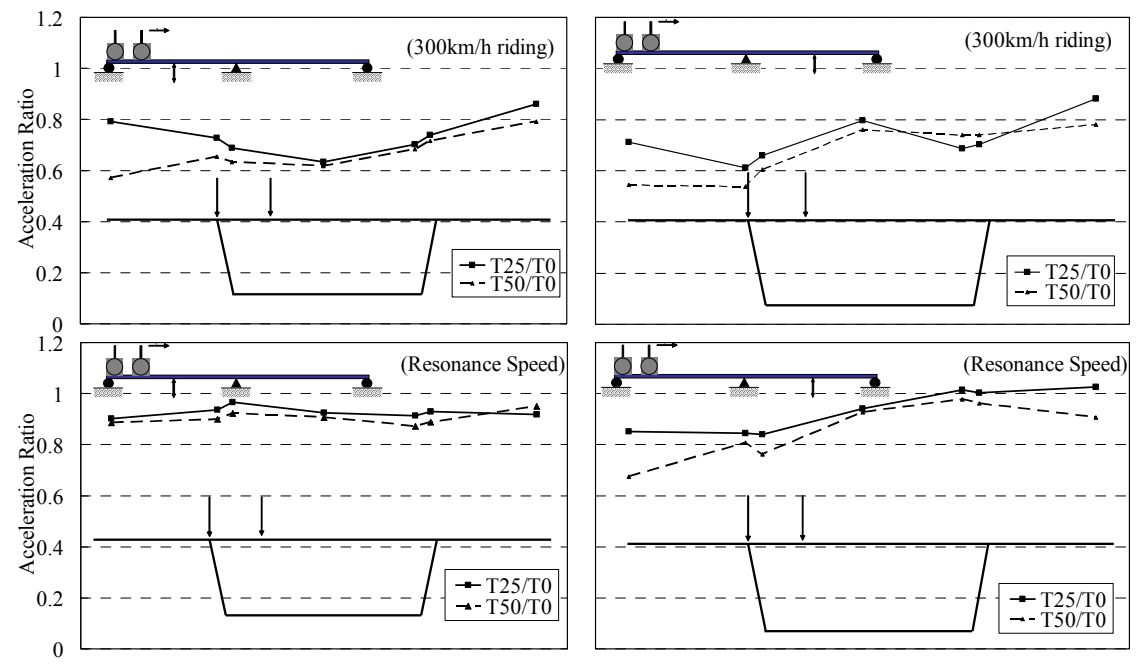

Figure 8: Reduction of the acceleration response brought by the added masses.

\section{Concluding remarks}

The most simple and efficient alternative to reduce the excessive acceleration responses occurring in high-speed railway bridges crossed by trains has been provided by means of small-size dampers and added masses. The applicability of these viscous dampers to reduce local vibrations has been examined theoretically and experimentally. The dynamic behavior of the bridge subjected moving loads by crossing trains has been analyzed using three-dimensional bridge model and tested at a field using various devices. Even if the solution reducing local vibration through the installation of such damping devices is also bringing some drawbacks in terms of maintenance, consistency of reduction effect and effectiveness, the method using additional masses to reduce excessive accelerations by simply increasing the mass is providing numerous advantages and, its significant effectiveness has been verified by means of theoretical study. The features found in this study are summarized hereafter. 
(1) Even if the solution reducing the acceleration responses using local vibration-reducing devices has been verified to be effective, this solution appeared to be extremely disadvantageous in terms of maintenance, which makes such method of poor economic viability.

(2) Based on the study results, the method adopting orifice dampers has been seen to be the most effective among the methods using local vibrationreducing damping devices.

(3) The solution reducing vibrations using additional masses appeared to be extremely economical and was assessed as a valuable method.

(4) Since the reduction effects appeared to not increase significantly with the size of the added masses, the selection of appropriate masses should be done with careful consideration.

(5) Field tests are previewed for the method applying added masses to reduce he local vibrations.

\section{Acknowledgements}

This study is part of a research on the R\&D for high-speed railway supported by the Korea Ministry of Construction and Transportation.

\section{References}

[1] Chang S.P., Kwark J.W. \& Kim S.I., Vibration of steel composite railway bridges subjected to high speed train. Journal of Korean Society for Steel Construction, 10(4), pp. 577-587, 1998.

[2] Ahn Y.J., Kim S.J. \& Shin Y.S., Dynamic Behavior of High-Speed Railway Bridges. Journal of Korean Society for Steel Construction, 20(3), pp. 375-384, 2000.

[3] Kim S.I., Bridge-train interaction analysis of high-speed railway bridges, Ph.D. Thesis. Seoul National University, Korea, 2000.

[4] Kwark J.W., Chin W.J., Kim Y.J. \& Kim B.S., Dynamic Behavior of Concrete Box Girder Bridge due to Riding Korean High-Speed Train. Journal of Korean Society for Steel Construction, 23(1), pp. 27-36, 2003. 